\title{
Influence of ultrasonic melt treatment on the formation of primary intermetallics and related grain refinement in aluminum alloys
}

\author{
L. Zhang $\cdot$ D. G. Eskin $\cdot$ L. Katgerman
}

Received: 17 January 2011 / Accepted: 9 March 2011 / Published online: 18 March 2011

(c) The Author(s) 2011. This article is published with open access at Springerlink.com

\begin{abstract}
Ultrasonic melt treatment (UST) is known to induce grain refining in aluminum alloys. Previous studies have clearly shown that in Al-Zr-Ti alloys, the primary $\mathrm{Al}_{3} \mathrm{Zr}$ intermetallics were dramatically refined by cavitation-assisted fragmentation, and a good refinement effect was achieved. In this article, Al-Ti, Al-Ti-Zr alloys, and some commercial aluminum alloys are used to analyze the effect of UST on primary intermetallics and grain refinement. The addition of a small amount of Al-3Ti-B master alloy is also studied in order to compare with the addition of $\mathrm{Ti}$ and $\mathrm{Zr}$ in commercial aluminum alloys. Experimental results show that the ultrasonic grain refining effect is not only related to the size of particles which are refined and/or dispersed by UST, but also related to an undercooling available for activation of these particles in the solidification process. Athermal heterogeneous nucleation theory is considered to explain the effect of size and distribution of substrate particles on the grain structure with different undercoolings. The distribution of primary particle sizes results in the distribution of required undercoolings. Grain refining occurs when the undercooling is large enough to activate the refined primary intermetallics or dispersed inoculants.
\end{abstract}

\footnotetext{
L. Zhang $(\bowtie) \cdot$ L. Katgerman

Department of Materials Science and Engineering, Delft

University of Technology, Mekelweg 2, 2628 Delft,

The Netherlands

e-mail: Liang.Zhang@tudelft.nl

D. G. Eskin

Brunel University, BCAST, Uxbridge UB8 3PH, UK
}

\section{Introduction}

In aluminum casting, a fine, equiaxed grain structure is normally desired, because it improves casting soundness by minimizing shrinkage, hot tearing, giving a more uniform distribution of second phases and microporosity on a fine scale, thus improving yield strength, fracture toughness, and other desirable properties $[1,2]$.

Generally, any factor which increases the number of nucleation sites or reduces growth rate, yields fine grains in the as-cast aluminum alloys [3]. Based on this, many techniques of grain refinement are available in casting practices, such as rapid solidification [4], deliberate addition of inoculants [5], and forced action upon melt which includes mechanical or magneto-hydrodynamic stirring and ultrasonic vibration $[6,7]$. The main mechanism of these techniques is increasing the number of nuclei by heterogeneous nucleation during solidification.

Ultrasonic melt treatment (UST) is known to induce grain refining in aluminum alloys. The basic principle is introduction of acoustic waves with a frequency higher than $17 \mathrm{kHz}$ into liquid metal. High frequency and high amplitude oscillations result in cavitation of the melt and also promote intense mixing through agitation. The reported mechanisms of grain refinement by UST range from affecting nucleation through local undercooling and wetting of substrates to fragmentation and transport of dendrites [7, 8].

Previous studies have clearly shown that in $\mathrm{Al}-\mathrm{Zr}-\mathrm{Ti}$ alloys, the primary $\mathrm{Al}_{3}(\mathrm{Zr}, \mathrm{Ti})$ intermetallics are dramatically refined, possibly by cavitation-assisted fragmentation. Aluminum grain refinement occurs when the UST is performed in the temperature range of primary solidification of $\mathrm{Al}_{3}(\mathrm{Zr}, \mathrm{Ti})$ [9]. The suggested mechanisms include the heterogeneous nucleation of ( $\mathrm{Al})$ on smaller intermetallic particles at higher undercooling [10]. 
According to athermal heterogeneous nucleation theory, the nucleation and growth of the solid phase are not only related to the geometry of the nucleant particles, but also are determined by the temperature (undercooling) [11]. As the temperature decreases, the solid begins to form on substrate particles and continue to grow along the substrate until the solid phase reaches the edge of the particle [12]. At this stage, the radius of curvature of solid approaches the critical value $D / 2$, where $D$ is the diameter of the particle at the geometrically limited undercooling $\Delta T_{\mathrm{g}}$, given by

$\Delta T_{\mathrm{g}}=\frac{4 \Gamma_{\mathrm{sl}}}{D}$

where $\Gamma_{\mathrm{sl}}$ is the Gibbs-Thomson coefficient between the stable embryo of the solid phase and the liquid. For an $\mathrm{Al}$ alloy, $\Gamma_{\mathrm{sl}}$ is about $9.12 \times 10^{-8} \mathrm{~K} \mathrm{~m}$ [12]. If the undercooling is larger than $\Delta \mathrm{T}_{\mathrm{g}}$, the critical radius becomes smaller than the radius of the particle. This solid can grow past the maximum curvature, since further growth of the solid leads to a decrease in the curvature. Otherwise, nucleation on such a particle is not successful. The growth of this solid will stop until the undercooling is larger than $\Delta T_{\mathrm{g}}$.

In this article, the role of UST on primary intermetallics and related grain refinement are studied using a selection of results from a large experimental program on the effects of ultrasound on the solidification of aluminum alloys. Alloys with primary intermetallic phases, i.e., $\mathrm{Al}-\mathrm{Ti}$ and $\mathrm{Al}-\mathrm{Zr}-\mathrm{Ti}$ alloys as well as some commercial aluminum alloys were cast under different cooling conditions after being treated with ultrasound. An Al-Ti-B master alloy, which increases the number of nuclei by heterogeneous nucleation, is also used in some experiments. The aim of this article is to discuss the link between the size of the primary intermetallics $\left(\mathrm{Al}_{3} \mathrm{Ti}, \mathrm{Al}_{3} \mathrm{Zr}\right)$ or inoculants $\left(\mathrm{TiB}_{2}\right)$ acting as substrates and grain refining effect achieved under different cooling conditions.

\section{Experimental procedure}

In this study, different casting conditions in combination with ultrasonic treatment were applied to $\mathrm{Al}-\mathrm{Ti}, \mathrm{Al}-\mathrm{Zr}-\mathrm{Ti}$, $\mathrm{Al}-\mathrm{Cu}, \mathrm{AA7075}$, and AA2024 alloys.

The experimental setup for UST comprised a $5-\mathrm{kW}$ ultrasonic generator, a $5-\mathrm{kW}$ magnetostrictive transducer with water-cooling system and a niobium ultrasonic horn (sonotrode). Experiments were performed at 4-kW generator power. The corresponding amplitude of vibrations was $40 \mu \mathrm{m}$ as measured by a vibrometer.

In order to obtain different cooling rates, a graphite crucible, a permanent copper mold, a steel mold, and direct-chill (DC) casting were used. All molds were preheated before casting. The cooling rates in the center of the samples during solidification were $0.8,2.0,2.0$, and $6 \mathrm{~K} / \mathrm{s}$, respectively. The temperature was measured by a $0.1 \mathrm{~mm}$ thin, open-tip K-thermocouple standing vertically in the center of the mold. Experimental alloys were prepared using $99.97 \mathrm{wt} \%$ pure Al, Al-5 wt\% Ti, Al-6 wt\% Zr, Al-50 wt $\% \mathrm{Cu}, \mathrm{Al}-3 \mathrm{wt} \% \mathrm{Ti}-1 \mathrm{wt} \% \mathrm{~B}$ master alloys. Commercial AA7075 and AA2024 alloys were obtained from industry (Aldel, Delfzijl, The Netherlands) as nongrain refined billets and used as master alloys. The casting conditions, alloy compositions, and their characteristics are summarized in Table 1.

In the case of solidifying in the graphite crucible, an Al-0.4 wt $\% \mathrm{Zr}-0.12 \% \mathrm{Ti}$ alloy was used. The alloy first was molten in an electric furnace, and then treated in the crucible (approx. $0.5 \mathrm{~kg}$ melt) by ultrasound for about $10-20 \mathrm{~s}$ from the liquidus of $\mathrm{Al}_{3} \mathrm{Zr}\left(790^{\circ} \mathrm{C}\right)$ to approximately $750{ }^{\circ} \mathrm{C}(0.4-0.45 \%$ solid phase $)$. After UST, the melt was poured into a graphite crucible. Without ultrasonic treatment, the melt was poured into a graphite crucible directly at a temperature of $790{ }^{\circ} \mathrm{C}$.

In the case of solidifying in the copper mold, an Al-0.4 wt\% Ti alloy and an AA2024 alloy were used.

Table 1 Casting conditions, chemical composition, and characteristics of experimental alloys

\begin{tabular}{|c|c|c|c|c|c|c|c|c|c|}
\hline \multirow[t]{2}{*}{ Alloy } & \multirow{2}{*}{$\begin{array}{l}\text { Temperature } \\
\text { of the phase } \\
\text { formation during } \\
\text { solidification }\left({ }^{\circ} \mathrm{C}\right)\end{array}$} & \multirow{2}{*}{$\begin{array}{l}\text { Temperature } \\
\text { range of } \\
\text { ultrasonic melt } \\
\text { treatment }\left({ }^{\circ} \mathrm{C}\right)\end{array}$} & \multicolumn{2}{|c|}{ Casting condition } & \multicolumn{4}{|c|}{ Composition (wt\%) } & \multirow{2}{*}{$\begin{array}{l}\text { Potential } \\
\text { substrates } \\
\text { for nucleation }\end{array}$} \\
\hline & & & Mold & $\begin{array}{l}\text { Cooling } \\
\text { rate, K/s }\end{array}$ & $\mathrm{Cu}$ & $\mathrm{Mg}$ & $\mathrm{Zn}$ & Additions & \\
\hline $\mathrm{Al}-\mathrm{Zr}-\mathrm{Ti}$ & $790\left(\mathrm{Al}_{3} \mathrm{Zr}\right) 662(\mathrm{Al})$ & $790-750$ & $\begin{array}{l}\text { Graphite } \\
\text { crucible }\end{array}$ & 0.8 & - & - & - & $0.4 \mathrm{Zr} ; 0.12 \mathrm{Ti}$ & $\mathrm{Al}_{3}(\mathrm{Zr}, \mathrm{Ti})$ \\
\hline $\mathrm{Al}-\mathrm{Ti}$ & $766\left(\mathrm{Al}_{3} \mathrm{Ti}\right) 660(\mathrm{Al})$ & $720-680$ & Copper mold & 2.0 & - & - & - & $0.4 \mathrm{Ti}$ & $\mathrm{Al}_{3} \mathrm{Ti}$ \\
\hline AA2024 & $646(\mathrm{Al})$ & $750-700$ & Copper mold & 2.0 & 3.33 & 1.30 & - & Al3Ti1B & $\mathrm{TiB}_{2}$ \\
\hline AA7075 & $765\left(\mathrm{Al}_{3} \mathrm{Zr}\right) 639(\mathrm{Al})$ & $720-640$ & $\begin{array}{l}\text { Through } \\
\text { launder to } \\
\text { steel mold }\end{array}$ & 2.0 & 1.46 & 2.14 & 5.43 & $\begin{array}{l}0.2 \mathrm{Zr} ; 0.07 \mathrm{Ti} \\
\text { Al3Ti1B }\end{array}$ & $\begin{array}{l}\mathrm{Al}_{3}(\mathrm{Zr}, \mathrm{Ti}) \\
\mathrm{TiB}_{2}\end{array}$ \\
\hline $\mathrm{Al}-\mathrm{Cu}$ & $650(\mathrm{Al})$ & 693 & DC casting & 6.0 & 3.9 & - & - & Al3Ti1B & $\mathrm{TiB}_{2}$ \\
\hline
\end{tabular}


In order to compare the different substrate particles, $0.02 \mathrm{wt} \% \mathrm{Ti}$ in the form of an Al3Ti1B master alloy was added to the AA2024 alloy. The alloys were first molten in an electric furnace, and then treated by ultrasound for about 10-20 s in the crucible (approx. $0.5 \mathrm{~kg}$ melt). The treated temperature for the Al- $0.4 \mathrm{wt} \% \mathrm{Ti}$ alloy was from 720 to $680{ }^{\circ} \mathrm{C}(0.66 \%$ solid phase). The AA2024 alloy was treated on the range from 750 to $700{ }^{\circ} \mathrm{C}$. After UST, the melt was poured into a copper mold. Samples without UST were produced by casting from $720^{\circ} \mathrm{C}$.

In order to analyze the influence of UST on a commercial wrought $\mathrm{Al}$ alloy under conditions simulating real casting practice, an AA7075 alloy with additions of $0.2 \mathrm{wt} \% \mathrm{Zr}$ and $0.07 \mathrm{wt} \% \mathrm{Ti}$ was used. A launder pouring system with casting into a long cylindrical steel mold was designed to simulate DC casting, as shown in Fig. 1. The cross section of the launder is $6 \times 5 \mathrm{~cm}^{2}$ with a length of $80 \mathrm{~cm}$. The melt was poured into the launder, then passed under the ultrasonic horn and solidified in the steel mold. The ultrasonic system was switched on before pouring. Temperature was monitored at both sides of the launder. The initial melt temperature was $720{ }^{\circ} \mathrm{C}$. The temperature dropped about $80^{\circ} \mathrm{C}$ when passing through the launder. Hence, the treatment was performed in the range of primary $\mathrm{Al}_{3}(\mathrm{Zr}, \mathrm{Ti})$ formation before the solidification of (Al) started.

The addition of a small amount of the Al3Ti1B master alloy rod was also studied in order to compare with the addition of Ti and Zr to AA7075 alloy. The AA7075 alloy with the addition of Al3Ti1B master alloy was cast in a steel mold with launder pouring system under the same conditions as described above.

Direct-chill casting of an Al-3.9 wt\% Cu alloy was also performed with addition of the Al3Ti1B master alloy rod. The UST was applied in the launder during DC casting, in a similar manner as during smaller scale experiments with

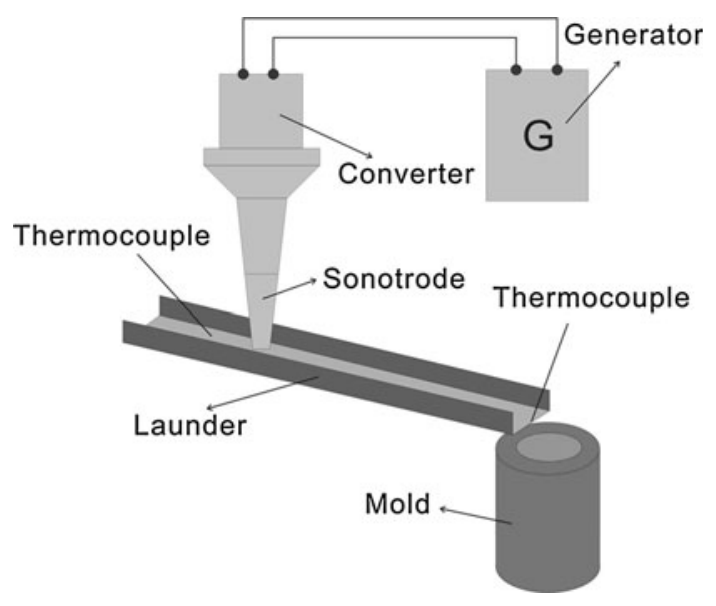

Fig. 1 Schematic view of the experimental launder pouring system the launder pouring system for DC casting simulation. The DC casting experimental setup is described in detail in reference [13]. A $1500-\mathrm{mm}$ long billet was cast in a $200-\mathrm{mm}$ hot top mold at a casting speed of $100 \mathrm{~mm} / \mathrm{min}$. Melt temperature in the furnace was $727^{\circ} \mathrm{C}$ and melt temperature in the launder was $693{ }^{\circ} \mathrm{C}$.

The chemical composition of all tested $\mathrm{Al}$ alloys was measured using a spark spectrum analyzer (Spectro, Kleve, Germany). The grain structures of all samples were examined in an optical microscope after being ground, polished, and electro-oxidized at $20 \mathrm{VDC}$ in a $3 \% \mathrm{HBF}_{4}$ water solution. Grain size was measured using the linear intercept method and the statistical analysis of the results was performed.

Morphology of the primary intermetallics particles were examined either in an optical microscope or in a scanning electron microscope (SEM) JSM 6500F. The composition of the particles was measured by energy dispersive X-ray spectrum analysis.

\section{Experimental results}

Effects of ultrasound applied to an Al-Ti alloy cast with a relatively high cooling rate

In aluminum casting, dramatic grain refinement can be observed when $\mathrm{Ti}$ present at hyperperitectic concentration $(>0.12 \mathrm{wt} \%)$ [14]. On one hand, $\mathrm{Al}_{3} \mathrm{Ti}$ is well known to be a good nucleation site for aluminum because multiple orientation relationships were found between $\mathrm{Al}_{3} \mathrm{Ti}$ and (Al) [15]. Primary $\mathrm{Al}_{3} \mathrm{Ti}$ phase which is naturally formed during solidification has a small value of the wetting angle $\theta$ and thus promotes heterogeneous nucleation. On the other hand, solute $\mathrm{Ti}$ in the liquid phase acts as growth restriction element for growing Al grains by contributing to the constitutional undercooling effect [16].

It has been suggested and demonstrated that ultrasonic treatment results in fragmentation of primary intermetallics, increasing their number [8-10]. In order to analyze the effect of ultrasonic treatment on formation of $\mathrm{Al}_{3} \mathrm{Ti}$ and related grain refinement in a hyperperitectic $\mathrm{Al}-\mathrm{Ti}$ alloy, the Al-0.4 wt\% Ti alloy was subjected to UST in the solidification range of $\mathrm{Al}_{3} \mathrm{Ti}$, from 720 to $680{ }^{\circ} \mathrm{C}$. Figure $2 \mathrm{a}, \mathrm{b}$ represents the microstructures of the Al-0.4 wt\% Ti alloy without UST. The size of $\mathrm{Al}_{3} \mathrm{Ti}$ particles was in the range 20-80 $\mu \mathrm{m}$. When UST was applied, two types of $\mathrm{Al}_{3} \mathrm{Ti}$ particles were found, as shown in Fig. 2c. Most of particles became dramatically smaller in size, ranging from 3 to $8 \mu \mathrm{m}$ (Fig. 2d).The larger particles with the size ranging 50-80 $\mu \mathrm{m}$ were fewer and are thought to form during solidification after UST (below $680{ }^{\circ} \mathrm{C}$ ). 

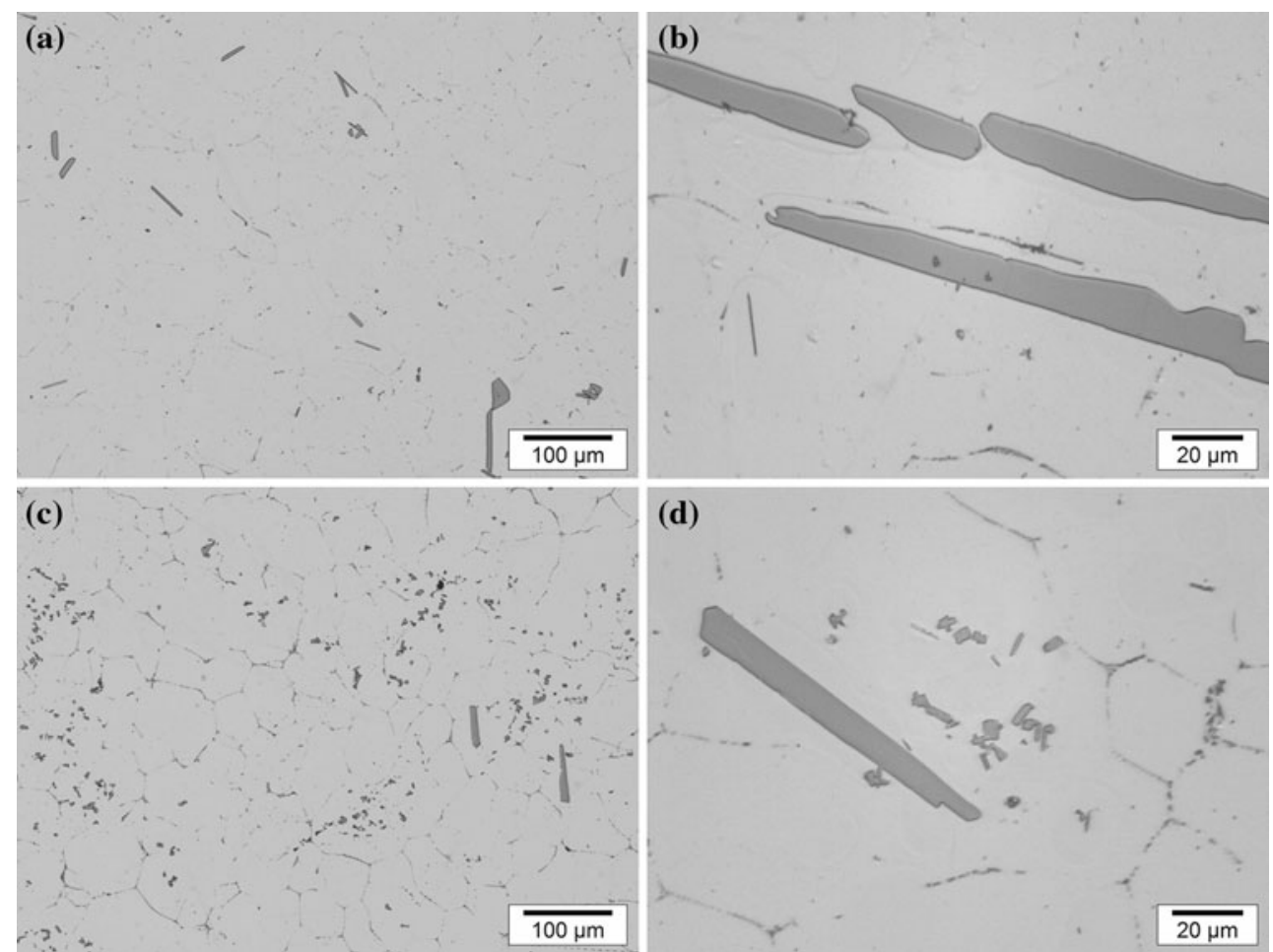

Fig. 2 Morphology of primary intermetallics in the Al-0.4 wt \% Ti alloy: a, b without ultrasonic melt treatment; c, d with ultrasonic melt treatment. Casting in the copper mold, cooling rate $2.1 \mathrm{~K} / \mathrm{s}$
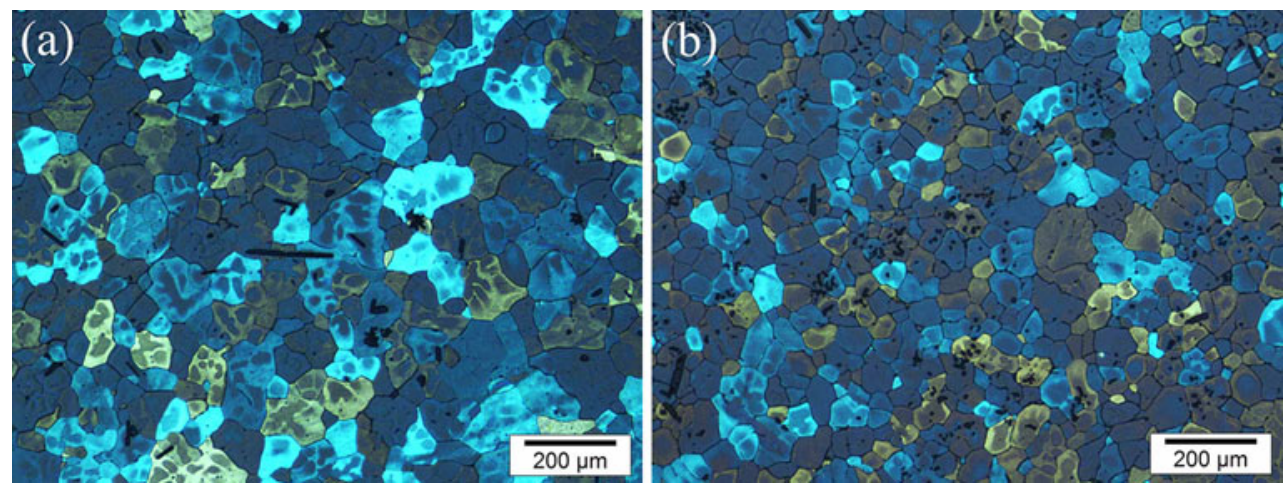

Fig. 3 Effect of UST on grain structure of the Al-0.4 wt\% Ti alloy: a without UST and $\mathbf{b}$ with UST. Casting in the copper mold, cooling rate $2 \mathrm{~K} / \mathrm{s}$

The refinement of primary intermetallics resulted in refining of $\mathrm{Al}$ grains, as shown in Fig. 3. The grain size reduces from 90 to $65 \mu \mathrm{m}$ when UST was applied to the Al-0.4 wt\% Ti alloy.

Effects of ultrasound applied to an $\mathrm{Al}-\mathrm{Zr}-\mathrm{Ti}$ alloy cast with a relatively low cooling rate

Previous experiments showed that additions of $\mathrm{Zr}$ and $\mathrm{Ti}$ led to great grain refinement efficiency under the influence of UST. In Al-Zr-Ti alloys, UST makes the primary intermetallics much smaller and facilitates Ti dissolution in the $\mathrm{Al}_{3} \mathrm{Zr}$ phase slightly changing its lattice parameters. The refinement of $\mathrm{Al}_{3} \mathrm{Zr}$ particles with more dissolved $\mathrm{Ti}$ leads to multiplication of potential substrates for nucleation. The detailed mechanism is discussed elsewhere [10].

In this research, we increased the amount of $\mathrm{Zr}$ and $\mathrm{Ti}$ to 0.4 and $0.12 \mathrm{wt} \%$, respectively, to increase the amount and size of primary intermetallics. The graphite crucible was used instead of a copper mold in previous experiments [9, 10] for solidification, which provided a lower cooling rate of $0.5-0.8 \mathrm{~K} / \mathrm{s}$.

Figure 4 gives the overview of primary intermetallics in the $\mathrm{Al}-0.4 \mathrm{wt} \% \mathrm{Zr}-0.12 \mathrm{wt} \% \mathrm{Ti}$ alloy cast with and 

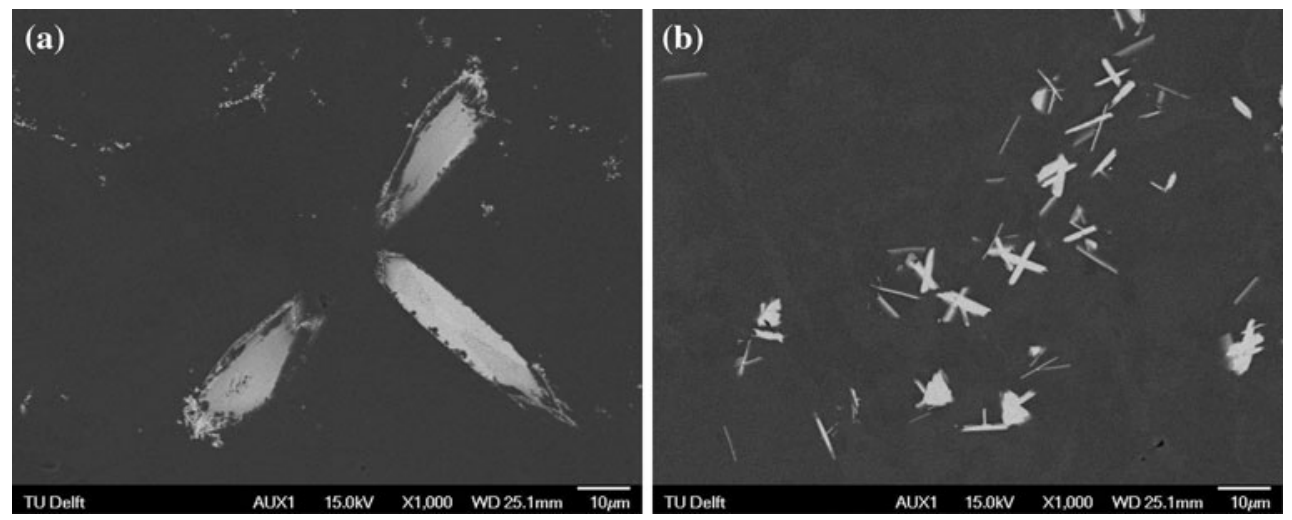

Fig. 4 Morphology of primary intermetallics in the Al-0.4 wt $\% \mathrm{Zr}-0.12 \mathrm{wt} \% \mathrm{Ti}$ : a without ultrasonic melt treatment and $\mathbf{b}$ with ultrasonic melt treatment. Casting in the graphite crucible, cooling rate $0.8 \mathrm{~K} / \mathrm{s}$

without UST. The UST was preformed in the solidification range of $\mathrm{Al}_{3}(\mathrm{Zr}, \mathrm{Ti})$ for $10 \mathrm{~s}$ starting from $790{ }^{\circ} \mathrm{C}$. The results are similar to that in the $\mathrm{Al}-0.4 \mathrm{wt} \% \mathrm{Ti}$ alloy. The particles size was reduced from $50-100 \mu \mathrm{m}$ without UST to $5-10 \mu \mathrm{m}$ when UST was applied. However, contrary to the experiments with the Al-Ti alloys (Fig. 3) and previous experiments [9] where $\mathrm{Al}-\mathrm{Zr}-\mathrm{Ti}$ alloys were cast in copper molds, the grain size after casting in the graphite crucible increases from $115 \mu \mathrm{m}$ without UST to $185 \mu \mathrm{m}$ when UST was applied.

Grain refinement in commercial aluminum alloys

In this section, some commercial aluminum alloys with small additions of either transition metals ( $\mathrm{Ti}, \mathrm{Zr}$ ) or the Al3Ti1B master alloy were produced under different casting conditions.

Figure 5 demonstrates the influence of UST on the grain size in the AA7075 alloy in the case of applying cavitation to the melt flow in the launder with subsequent solidification in the steel mold. The UST of the AA7075 alloy with $0.07 \mathrm{wt} \% \mathrm{Ti}$ and $0.20 \mathrm{wt} \% \mathrm{Zr}$ reduced the grain size from 350 to $45 \mu \mathrm{m}$ (Fig. 5, left side). The structure after UST

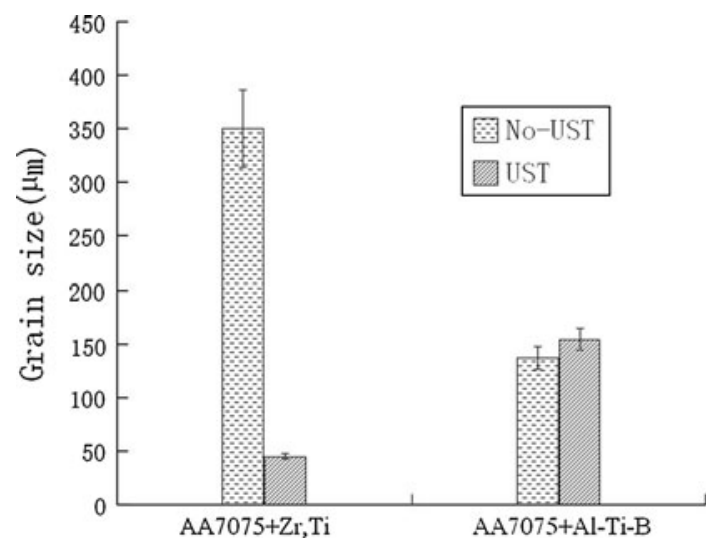

Fig. 5 Effect of UST on the grain size of the AA7075 aluminum alloy with different additions. Casting in the steel mold, UST performed in the launder. Cooling rate $2 \mathrm{~K} / \mathrm{s}$

became equiaxed and non-dendritic, as presented in Fig. 6 . However, when Al3Ti1B master alloy was added in typical quantities, the UST did not lead to additional grain refinement (Fig. 5, right side). The grain size after UST even increased from 135 to $155 \mu \mathrm{m}$. Similar results were
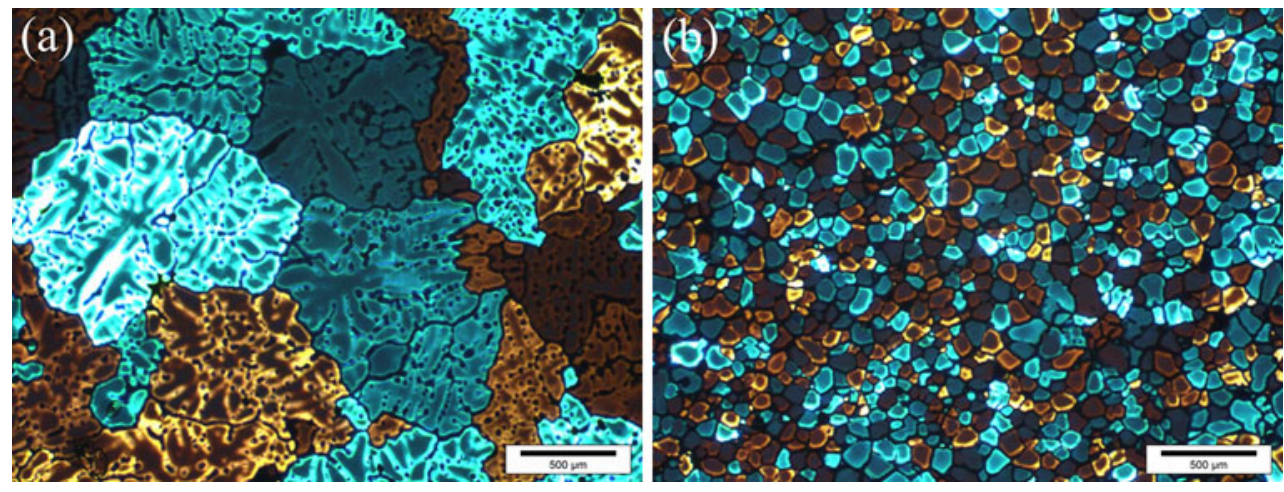

Fig. 6 Effect of UST on grain structure of AA7075 Al alloy: a without UST and b with UST in the launder. Casting in the steel mold. Cooling rate $2 \mathrm{~K} / \mathrm{s}$ 


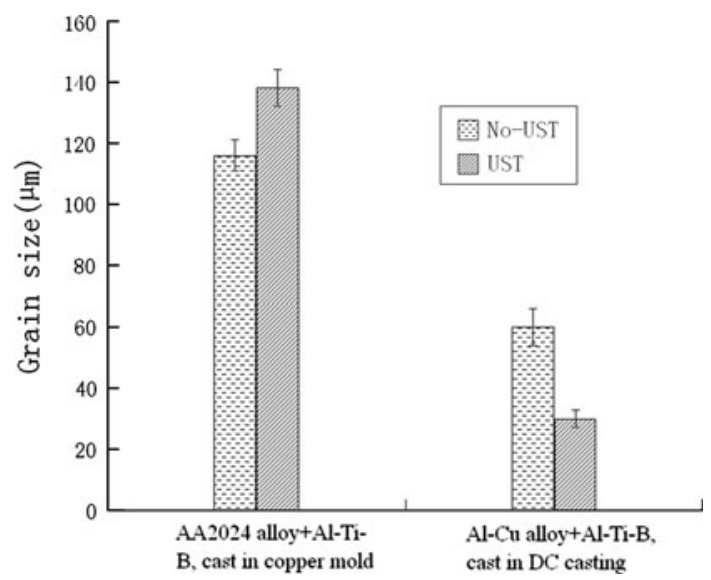

Fig. 7 Effect of UST on the grain size of the Al-Cu-based alloys cast under different casting conditions. Cooling rate in the copper mold was $2 \mathrm{~K} / \mathrm{s}$, during DC casting- $6 \mathrm{~K} / \mathrm{s}$

obtained when UST was applied to the AA2024 alloy with addition of Al3Ti1B while casting in the copper mold, which has the same cooling rate as the steel mold, as illustrated in Fig. 7 (left side). However, the grain size after UST decreased twofold, from 60 to $30 \mu \mathrm{m}$, in the $\mathrm{Al}-\mathrm{Cu}$ alloy with Al3Ti1B addition when UST was applied upon DC casting (Fig. 7, right side).

\section{Discussion}

Figure 8 is a summary of all experiments and results presented above. The results show that UST refines primary intermetallics, which potentially may increase the number of nucleant particles, promoting heterogeneous nucleation. However, the decreased primary particles size requires larger undercooling for their activation according to the athermal heterogeneous nucleation theory. Therefore, the distribution of primary particle sizes results in a distribution of required undercoolings.

Figure 9 is a schematic view of the effect of UST on particles size distribution. When UST was applied, the main peak of particle size distribution shifts largely to the left, which represents most of primary particles getting smaller. Simultaneously, the number of large particles decreases. To explain the effect of grain refinement, we assume that there is critical undercooling $\Delta T_{\mathrm{gc}}$ which cannot activate most of small primary particles in the case of UST with subsequent solidification at lower cooling rates. In the experiments, the primary particles after UST became about $3-10 \mu \mathrm{m}$ in size in both the $\mathrm{Al}-\mathrm{Ti}$ and $\mathrm{Al}-$ $\mathrm{Zr}-\mathrm{Ti}$ alloys, which corresponds to the critical undercooling $\Delta T_{\mathrm{gc}}$ of $0.044 \mathrm{~K}$ as estimated using Eq. 1. Usually in casting practice, the undercooling that can be achieved during casting of aluminum alloys in metallic molds is about $0.2 \mathrm{~K}$ [17]. So the undercooling $\Delta \mathrm{T}$ reached upon solidification in the copper mold can be well more than $\Delta T_{\mathrm{gc}}$ of $0.044 \mathrm{~K}$, therefore the refinement of primary intermetallics results in refining effect on $\mathrm{Al}$ grains in the Al-0.4 wt\% Ti alloy, as shown in Fig. 3. The grain size reduces from 90 to $65 \mu \mathrm{m}$ when UST was applied. The constitutional undercooling effect caused by Ti might further enhance the nucleation potency for fine $\mathrm{Al}_{3} \mathrm{Ti}$ particles.

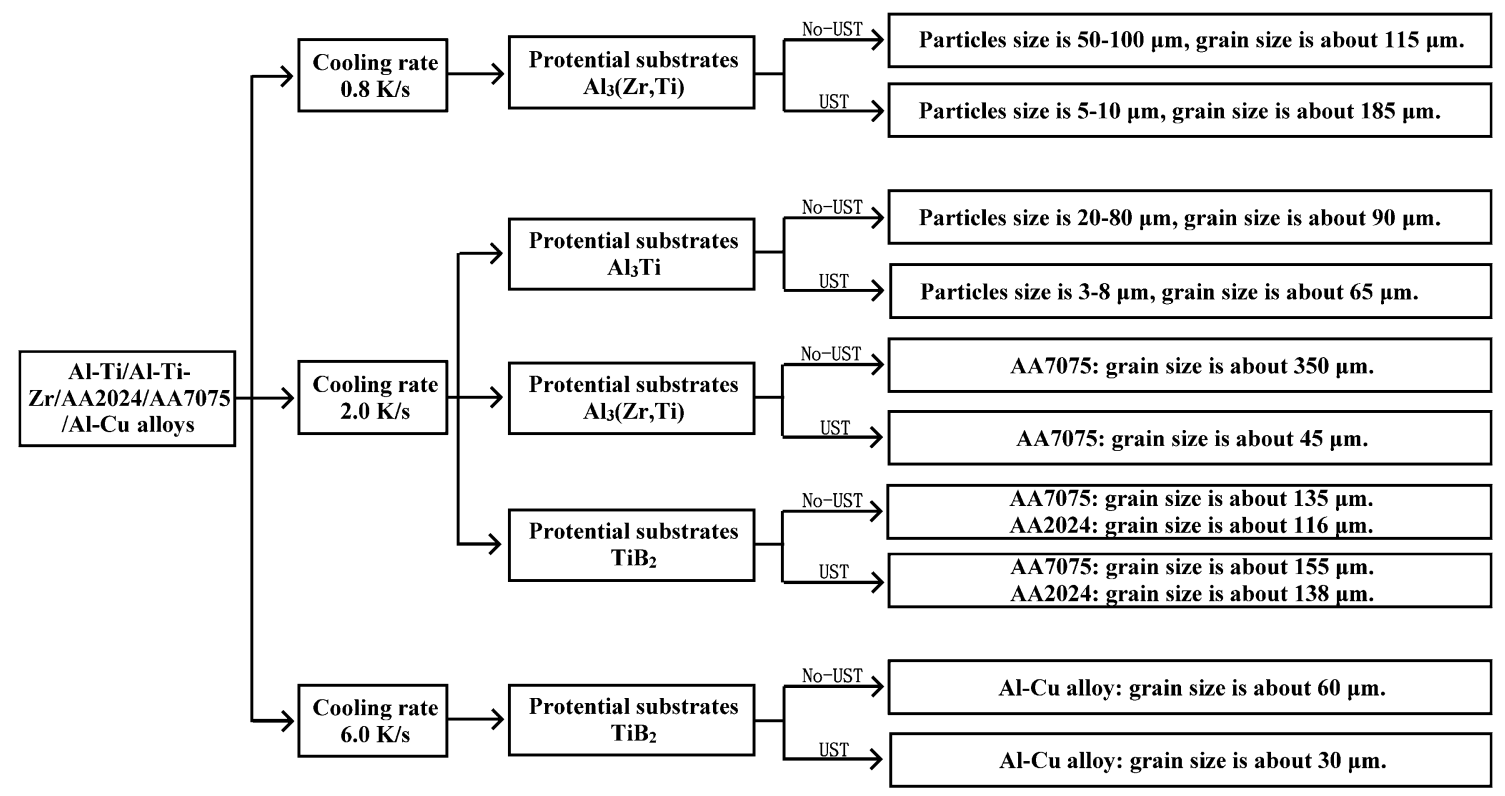

Fig. 8 A flow chart of the performed experiments and results 


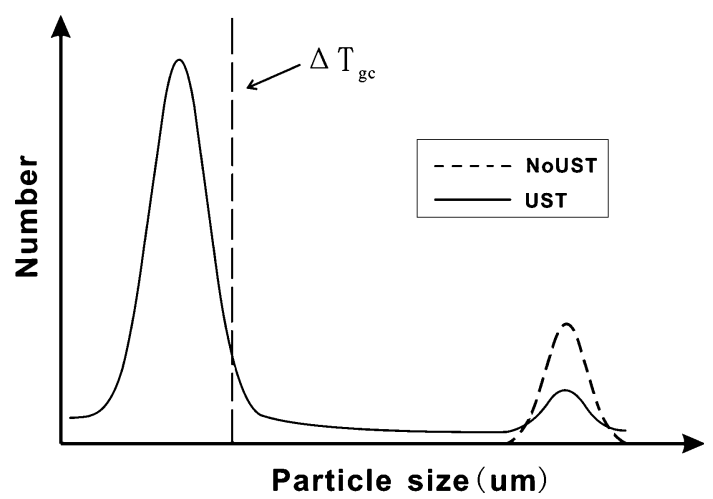

Fig. 9 Schematic view of the effect of UST on size distribution of particles. $\Delta T_{\mathrm{gc}}$ is critical undercooling for nucleation under UST

However, in the case of the lower cooling rate in the graphite crucible, the grain size increases from $115 \mu \mathrm{m}$ without UST to $185 \mu \mathrm{m}$ when UST is applied to Al$0.4 \mathrm{wt} \% \mathrm{Zr}-0.12 \mathrm{wt} \% \mathrm{Ti}$ alloy. Note that in our previous experiments with casting in metallic molds $\mathrm{Al}-\mathrm{Zr}-\mathrm{Ti}$ alloys showed remarkable grain refining after UST [9].

When looking at these results from the positions of required undercooling and substrate size, it appears that the absence of grain refinement upon slow cooling can be logically explained. On one hand, the undercooling in the experiment with the low cooling rate might be less than the critical undercooling $\Delta T_{\mathrm{gc}}$ (situation depicted in Fig. 9), which means that the undercooling is not enough to activate those smaller intermetallics fragmented by UST. As a result, the grain size increases with intermetallic refining because less large particles are available for nucleation when UST was used. On the other hand, UST promotes the dissolution of $\mathrm{Ti}$ in $\mathrm{Al}_{3} \mathrm{Zr}$ particle, increasing the disregistry between crystal lattices of $\mathrm{Al}$ and $\mathrm{Al}_{3} \mathrm{Zr}$ particles [10]. The larger disregistry and corresponding interfacial energy result in a higher heterogeneous nucleation energy barrier. The increased heterogeneous nucleation energy barrier may lead to the delay of nucleation to larger undercooling before the free growth could be become possible. As a result, the activation of more refined particles and, consequently, greater grain refining effect, requires larger undercooling such as has been apparently achieved in the $\mathrm{Al}-0.4 \mathrm{wt} \% \mathrm{Ti}$ alloy and in the previous experimental results with $\mathrm{Al}-\mathrm{Zr}-\mathrm{Ti}$ alloys cast in a copper mold [9]. However, if the undercooling is not enough, the efficiency of UST may be inhibited or even aggravated.

As discussed above, UST increases the number of potent nucleants and promotes grain refinement under appropriate casting conditions. So in the experiments with the AA7075 alloy containing $\mathrm{Zr}$ and $\mathrm{Ti}$ and cast in the steel mold $(2 \mathrm{~K} / \mathrm{s})$ after UST in the melt flow in the launder, it was assumed that UST would produce fine $\mathrm{Al}_{3} \mathrm{Zr}$ particles which would be activated by the sufficient undercooling and facilitate grain refinement. This was confirmed as illustrated in Fig. 5 (left side). However, the same experiment but performed with the alloys with $\mathrm{TiB}_{2}$ additions did not produce any additional grain refinement after UST (Fig. 5, right side). Neither the experiment with the AA2024 alloys with $\mathrm{TiB}_{2}$ addition cast in the copper mold with the same cooling rate $2 \mathrm{~K} / \mathrm{s}$. Only DC casting of the Al- $\mathrm{Cu}$ alloy with $\mathrm{TiB}_{2}$ additions demonstrated considerable grain refinement after UST. So what is the difference?

To answer this question, the cooling rate and the mechanism of grain refinement by $\mathrm{TiB}_{2}$ should be firstly considered. In general, it is accepted that $\mathrm{TiB}_{2}$ acts as nucleation site for $(\mathrm{Al})$ either directly or through the $\mathrm{Al}_{3} \mathrm{Ti}$ layer which disappears during further solidification [18]. The average $\mathrm{TiB}_{2}$ particle size in a commercial Al3Ti1B grain refining rod is around $1 \mu \mathrm{m}$ [19], which corresponds with the critical undercooling $\Delta T_{\mathrm{gc}}$ of $0.36 \mathrm{~K}$. According to the typical achievable undercooling $0.2 \mathrm{~K}$, the most active $\mathrm{TiB}_{2}$ particles are larger than $5 \mu \mathrm{m}$. In addition, titanium borides are usually agglomerated and only some fraction of them is available as solidification sites under typical casting conditions. According to athermal heterogeneous nucleation theory, the finer $\mathrm{TiB}_{2}$ particles mean that a larger undercooling is needed for their free-growth activation. The UST might disperse agglomerated $\mathrm{TiB}_{2}$ particles, which would result in finer separated particles thus increasing the demand for the greater undercooling $\Delta T_{\mathrm{gc}}$ in the solidification process. In casting, larger undercooling usually results from a higher cooling rate. DC casting may provide just that, the measured cooling rate is 6 versus $2 \mathrm{~K} / \mathrm{s}$ in the metallic molds used. Therefore, when the steel or copper mold was used (relatively low cooling rate compared to DC casting), a lower percentage of $\mathrm{TiB}_{2}$ particles and only the larger ones could act as solidification sites because of dispersion of $\mathrm{TiB}_{2}$ particles caused by UST. However, in DC casting the undercooling might be large enough to activate at least part of these dispersed $\mathrm{TiB}_{2}$ particles, increasing the amount of nucleants and reducing the grain size in the DC-cast alloy.

\section{Conclusions}

Ultrasonic treatment of molten aluminum alloys can refine the intermetallics dramatically when it is applied in the temperature range of their primary solidification. These refined particles may be involved in a solidification process as solidification sites and promote the grain refining effect by heterogeneous nucleation under proper casting condition. Whether those particles would result in a further grain refining effect in aluminum alloys depends on the undercooling achieved during solidification. The grain refining effect occurs when the undercooling is large enough to 
activate those refined primary intermetallics. The required undercooling is a function of the crystal structure of the substrate (which characterizes the potency of the grain refiner) and its size (which characterizes the possibility of the free growth). The refinement of the potential substrates at the same alloy composition means the multiplication of the solidification sites, which in combination with right undercooling will result in improved grain refinement. In commercial Al alloys with additions of $\mathrm{Zr}$ and $\mathrm{Ti}$, ultrasonic processing is promising. The grain structure can be refined dramatically by UST performed in the melt flow in the launder. The results show that the grain refinement of alloys with addition of an Al-Ti-B master alloy may also be related to the substrate particle size in the melt under UST. The dispersed, fine $\mathrm{TiB}_{2}$ particles formed upon UST increase the demand for undercooling required for grain refinement. With the high cooling rates during casting, e.g., upon DC casting, the combination of Al-Ti-B master alloy and UST is an efficient way to gain additional grain refinement effect.

Acknowledgements The Authors would like to acknowledge the support of Materials innovation institute for the part of this study. Cooperation with Dr. T.V. Atamanenko is especially appreciated. L. Zhang would like to thank China Scholarship Council and Prof. J.S. Zhang for providing the scholarship for the PhD study at TU Delft.

Open Access This article is distributed under the terms of the Creative Commons Attribution Noncommercial License which permits any noncommercial use, distribution, and reproduction in any medium, provided the original author(s) and source are credited.

\section{References}

1. Murty BS, Kori SA, Chakraborty M (2002) Int Mater Rev 47:3

2. Davis JR (1993) Aluminum and aluminum alloys. ASM specialty handbook. ASM International, Metals Park

3. Flemings MC (1974) Solidification processing. McGraw-Hill, New York

4. Trivedi R, Kurz W (1994) Int Mater Rev 39:49

5. Mohanty PS, Gruzleski JE (1995) Acta Metall Mater 43:2001

6. Vives C (1998) J Cryst Growth 158:118

7. Abramov OV (1994) Ultrasound in liquid and solid metals. CRC Press, Boca Raton

8. Eskin GI (1998) Ultrasonic treatment of light alloy melts. Gordon and Breach Science Publishers, Amsterdam

9. Atamanenko TV, Eskin DG, Zhang L, Katgerman L (2010) Metall Mater Trans A 41:2056

10. Atamanenko TV, Eskin DG, Sluiter M, Katgerman L (2011) J Alloy Compd 509:57

11. Quested TE, Greer AL (2005) Acta Mater 53:2683

12. Dantzig JA, Rappaz M (2009) Solidification. CRC Press, Boca Raton

13. Eskin DG, Zuidema J Jr, Savran VI, Katgerman L (2004) Mater Sci Eng A 384:232

14. Crossley FA, Backerud L (1951) J Met 191:1143

15. Davies IG, Dennis JM, Hellawell A (1970) Metall Trans 1:275

16. Quested TE, Greer AL (2005) Acta Mater 53:4643

17. Quested TE, Greer AL (2004) Acta Mater 52:3859

18. Easton M, Stjohn D (1999) Metall Mater Trans A 30A:1613

19. Schneider WA, Quested TE, Greer AL, Cooper PS (2003) In: Crepeau PN (ed) Light Metals 2003. TMS, Warrendale 